\title{
Angiostatin levels in systolic heart failure patients with chronic kidney disease
}

\author{
Ismail Erturk', (i) Erdim Sertoglu², Taner Ozgurtas², (i) Fatih Yesildal2', (i) Ramazan Acar', (i) Birol Yildiz', \\ Fevzi Nuri Aydin'2, Galip Buyukturan', (1) Kenan Saglam'
}

'Department of Internal Medicine, University of Health Sciences, Gulhane Training and Research Hospital, Ankara, Turkey

2Department of Medical Biochemistry, University of Health Sciences, Gulhane Training and Research Hospital, Ankara, Turkey

\begin{abstract}
Objectives: Heart failure (HF) with reduced ejection fraction (HFrEF) is defined as an ejection fraction (EF) of less than $40 \%$. An EF of $40 \%$ to $50 \%$ is known as HF with mid-range EF, which is considered a subgroup of HF with preserved ejection fraction, rather than HFrEF. Angiostatin inhibits angiogenesis and the proliferation of mesenchymal stem cells. Though many studies in the literature have focused on the effect of angiostatin on endothelial cell apoptosis, studies about angiostatin levels in HF patients are limited. The aim of this study was to evaluate the angiostatin level in systolic HF patients with chronic kidney disease (CKD).

Methods: A group of 69 individuals, consisting of patients with a diagnosis of systolic HF with CKD ( $\mathrm{n}=29$ ) and healthy $(n=40)$ subjects, was included in the current study. Serum angiostatin, plasma N-terminal pro-brain type natriuretic peptide, and creatinine levels were assessed, and transthoracic echocardiography was performed.

Results: The angiostatin level of the patient group was significantly higher than that of the control group (median: $163 \mathrm{ng} / \mathrm{mL}$ [ $25^{\text {th }}-75^{\text {th }}$ interquartile range: $48-336 \mathrm{ng} / \mathrm{mL}$ ] and median: $58.14 \mathrm{ng} / \mathrm{mL}$ [25 $5^{\text {th }}-75^{\text {th }}$ interquartile range: 18.1 $167 \mathrm{ng} / \mathrm{mL}$ ], respectively; $\mathrm{p}=0.02$ ). The angiostatin level of HF patients receiving beta blocker therapy was significantly higher than that of the HF patients who were not taking a beta blocker $(105.3 \mathrm{ng} / \mathrm{mL}[50.7-220.7 \mathrm{ng} / \mathrm{mL}] \mathrm{and} 70.4 \mathrm{ng} /$ $\mathrm{mL}[35-224 \mathrm{ng} / \mathrm{mL}]$, respectively; $\mathrm{p}=0.02)$.

Conclusion: To the best of our knowledge, this study is the first to examine this subject. Angiostatin may be an important marker in systolic HF patients with CKD. The use of a beta blocker may inhibit angiogenesis and induce apoptosis in HF patients with CKD. Further studies are required.

Keywords: Angiogenesis, angiostatin, chronic kidney disease, heart failure
\end{abstract}

$C^{n}$ $\mathrm{KD}$ is characterized by alterations in kidney function, which manifest in various ways, depending upon the underlying causes and the severity of the disease [1-3]. Heart failure (HF) with reduced ejection (HFrEF) occurs when the ejection fraction (EF) is less than $40 \%$. When the $\mathrm{EF}$ is in the range of $40 \%$ to $50 \%$, it is classified as $\mathrm{HF}$ with mid-range $\mathrm{EF}$ (HFmrEF). These conditions are considered systolic HF $[4,5]$.

Angiostatin is a naturally occurring protein, formed through the process of the fragmentation of plasminogen. It is a potent endogenous inhibitor of mesenchymal stem cells, endothelial cells, and angiogenesis [6]. Many studies have focused on the effect of angiostatin on endothelial cell apoptosis, though the mechanisms of action are still not yet completely understood $[7,8]$.

The binding of angiostatin to plasma membrane-localized adenosine triphosphate (ATP) synthase suppresses ATP metabolism in the endothelial cells, and thus downregulates endothelial cell proliferation [9].

Address for correspondence: Ismail Erturk, MD. Department of Internal Medicine, University of Health Sciences, Gulhane Education and Research Hospital, Ankara, Turkey

Phone: +90 5058726378 E-mail: ierturk@hotmail.com ORCID: 0000-0001-6835-0988

Submitted Date: March 12, 2019 Accepted Date: March 21, 2019 Available Online Date: June 13, 2019

${ }^{\circ}$ Copyright 2019 by International Journal of Medical Biochemistry - Available online at www.internationalbiochemistry.com OPEN ACCESS This work is licensed under a Creative Commons Attribution-NonCommercial 4.0 International License. 
According to the literature, local synthesis of angiostatin following acute kidney disease suggests a possible role for angiostatin in this activity [10].

However, studies examining the relationship between plasma angiostatin and the characteristics and laboratory findings of systolic HF patients with CKD are limited. The hypothesis of this study was that an increase in angiostatin in the plasma might contribute to the impairment of angiogenesis in $\mathrm{HF} \mathrm{pa-}$ tients with CKD, and the relationship with the laboratory findings and medications of the patients were investigated.

\section{Materials and Methods}

\section{Study sample and study protocol}

This comparative, cross-sectional study was conducted with a total of 69 individuals: HF patients with CKD $(n=29)$ and participants without disease $(n=40)$ who presented at the nephrology or internal medicine outpatient facilities of Gulhane Training and Research Hospital, Ankara, Turkey, between 2011 and 2013. All of the procedures applied were performed in accordance with the ethical standards of the committees on human trials (institutional and national) and the Declaration of Helsinki. This study was approved by Gulhane Education and Research Hospital local ethics council with protocol number 1491-181-12/1539-491 on February 28, 2012. The EF was less than $40 \%$ and between $40 \%$ and $50 \%$, respectively, for the patients with HFrEF and HFmrEF. All of the patients and the control group participants were older than 18 years of age. In all, 17 of the participants in the control group were male and 23 were female. In the patient group, 17 were male, and 12 were female. The diagnosis of systolic HF was based on the symptoms, a physical examination (European Society of Cardiology, 2016), echocardiographic results, and N-terminal pro-brain natriuretic peptide (NT-proBNP) level. Patients with rheumatic disease or clinical signs of infection, atrial fibrillation, chronic obstructive pulmonary disease, high C-reactive protein (CRP) value ( $>5 \mathrm{mg} / \mathrm{L}$ ) and/or known malignancy were excluded from the study. The Chronic Kidney Disease Epidemiology Collaboration (CKD-EPI) equation was used to determine the glomerular filtration rate (GFR) [11]. There were 15 patients with diabetes mellitus in the patient group and all were on insulin treatment.

The serum angiostatin level of the HF patients with CKD and the control group were compared. The angiostatin level and the clinical findings of demographic features, laboratory results, comorbidities, and medications in the HF patient were compared with the CKD group to assess possible relationships.

After an overnight fast, baseline blood samples were drawn from an antecubital vein in each participant into a BD Vacutainer venous blood collection tube containing clot activator and gel for serum isolation (Becton, Dickinson and Company, Franklin Lakes, NJ, USA). Centrifugation at $2000 \mathrm{~g}$ for $10 \mathrm{~min}$ utes was performed to separate the serum. A portion was used for analysis of the biochemical parameters without freezing, while 2 to $3 \mathrm{~mL}$ of the serum sample was aliquoted and immediately frozen at $-80^{\circ} \mathrm{C}$ for further analysis of angiostatin.

High sensitivity C-reactive protein (hs-CRP) in the serum was evaluated using the immunoturbidimetric fixed rate method and an AU5800 autoanalyzer (Beckman Coulter, Inc., Brea, CA, USA). Enzymatic and colorimetric methods were used to measure alanine aminotransferase (ALT), aspartate aminotransferase (AST), fasting blood glucose, urea, and creatinine with the same autoanalyzer. An automated blood cell counter (ABX Pentra 120, Horiba Ltd., Kyoto, Japan) was used for complete blood count analysis.

The angiostatin level was analyzed using quantitative enzyme-linked immunosorbent assay (ELISA) kits (Cat.No: CKE90461; Hangzhou Eastbiopharm Co., Ltd, Hangzhou, China). Measurements were made using the Bio-Tek Synergy HT ELISA plate reader (Biotek Instruments Inc., Winooski, VT, USA). The intra-assay coefficient of variation (CV) and inter-assay CV results were $<10 \%$ and $<12 \%$, respectively, while the minimum detectable dose of angiostatin was less than $20 \mathrm{ng} / \mathrm{mL}$.

\section{Statistical analysis}

The clinical characteristics, history of medications, and the laboratory results of the participants were compared according to the angiostatin level.

SPSS for Windows, Version 16.0 (SPSS Inc., Chicago, IL, USA) was used to perform the statistical analyses. Discontinuous variables were shown as numbers and percentages for the descriptive statistics, and mean \pm SD or median $\left(25^{\text {th }}-75^{\text {th }}\right.$ percentile, interquartile range) was used for the evaluation of continuous variables. Normality of the data was evaluated with the Kolmogorov-Smirnov test.

The Mann-Whitney $U$ test was applied to assess differences between independent groups and the Spearman test was used for nonparametric correlations. P values of less than 0.05 were considered statistically significant.

\section{Results}

The differences between HF patients with CKD and the control group are presented in Table 1 . There was no statistically significant difference between groups in terms of age, gender, or levels of glucose, ALT, AST, hemoglobin, platelet count, hsCRP, white blood cell count, or erythrocyte sedimentation rate. Levels of angiostatin, urea, creatinine, and NT-ProBNP were significantly higher in patients with CKD than in the controls $(p<0.001$ for all). Also, the glomerular filtration rate (GFR) and EF were significantly lower in HF patients with CKD than in the controls $(p \leq 0.05)$.

In correlation analysis, serum angiostatin levels were not significantly correlated with GFR, urea, creatinine, EF, or NT-ProBNP.

A significantly higher level of angiostatin was observed in $\mathrm{HF}$ patients with CKD who used a beta blocker than in the HF patients who did not use a beta blocker. No significant difference 
Table 1. Comparison of demographic and laboratory features of HF patients with CKD and control group

\begin{tabular}{|c|c|c|c|}
\hline & $\begin{array}{l}\text { Control } \\
(n=40)\end{array}$ & $\begin{array}{l}\text { Patients } \\
(n=29)\end{array}$ & $\mathbf{P}$ \\
\hline Age, years & $71.53(48-86)$ & $71.72(49-87.0)$ & 0.695 \\
\hline Glucose (fasting), mg/dL & $99.07(80-137)$ & $115.72(56-332)$ & 0.09 \\
\hline Urea, mg/dL & $36.75(5-45)$ & $119.75(43-244)$ & $<0.001$ \\
\hline AST, U/L & $23.00(12.0-70.0)$ & $25.00(10-64)$ & 0.216 \\
\hline $\mathrm{ALT}, \mathrm{U} / \mathrm{L}$ & $21.00(6.0-83.0)$ & $16.00(2-56)$ & 0.266 \\
\hline Hemoglobin, g/dL & $13.28(9.3-16.22)$ & $11-4(7.5-15.6)$ & 0.655 \\
\hline Platelet, $10^{3} / \mathrm{mm}^{3}$ ) & 271(91-394) & $222(87-507)$ & 0.275 \\
\hline$E F, \%$ & $60.57(55-65)$ & $37.00(15-45)$ & $<0.001$ \\
\hline Angiostatin, $\mathrm{ng} / \mathrm{mL}$ & $58.14(18.1-167)$ & $163(48-336)$ & $<0.001$ \\
\hline
\end{tabular}

*Non-normally distributed variables are presented as median (minimum-maximum); ALT: Alanine aminotransferase; AST: Aspartate aminotransferase; CKD: Chronic kidney disease; CRP: C-reactive protein; EF: Ejection fraction; GFR: Glomerular filtration rate; HF: Heart failure; NT-ProBNP: N-terminal pro-brain natriuretic peptide.

Table 2. Comparison of angiostatin levels and clinical information of patients with HF patients with CKD

\begin{tabular}{|c|c|c|c|c|}
\hline & \multirow[b]{2}{*}{$\mathbf{n}$} & \multicolumn{3}{|c|}{ Angiostatin } \\
\hline & & Mean \pm SD & $\mathbf{P}^{1}$ & $\mathbf{P}^{2}$ \\
\hline Control & 40 & $58.14(18.1-167)$ & & \\
\hline DM (-) & 14 & $88.9(60-283.1)$ & 0.24 & $<0.001$ \\
\hline $\mathrm{DM}(+)$ & 15 & $121.8(58.7-260.6)$ & & \\
\hline CAD (-) & 19 & $102.8(60.7-212.1)$ & 0.21 & 0.044 \\
\hline CAD (+) & 10 & $88.2(66-134.6)$ & & \\
\hline HT (-) & 13 & $92.3(45.7-200.7)$ & 0.34 & $<0.001$ \\
\hline $\mathrm{HT}(+)$ & 16 & $107.8(62.3-282.1)$ & & \\
\hline ACE Inh or ARB (-) & 4 & $82.2(66-211.1)$ & 0.112 & $<0.001$ \\
\hline ACE Inh or ARB (+) & 25 & $134.5(50.7-201.1)$ & & \\
\hline Beta blocker (-) & 15 & $70.4(35-224)$ & 0.02 & 0.004 \\
\hline Beta blocker (+) & 14 & $105.3(50.7-220.7)$ & & \\
\hline ASA (-) & 15 & $113(66.1-200.1)$ & 0.447 & 0.005 \\
\hline ASA (+) & 14 & $87.2(59.7-210.6)$ & & \\
\hline CCB (-) & 17 & $82.5(58.7-228.7)$ & 0.521 & $<0.001$ \\
\hline $\mathrm{CCB}(+)$ & 12 & $80.4(79.1-282.1)$ & & \\
\hline
\end{tabular}

*Variables that were not normally distributed are presented as median (minimummaximum); ACEI: Angiotensin-converting enzyme inhibitor; ARB: Angiotensin II receptor blocker; ASA: Acetylsalicylic acid; CAD: Coronary artery disease;

CCB: Calcium channel blocker; CKD: Chronic kidney disease; DM: Diabetes mellitus; HF: Heart disease; HT: Hypertension; $\mathrm{P}^{1}$ : Comparison of the accompanying diseases or medications used in patient group; $\mathrm{P}^{2}$ : Comparison of the accompanying diseases or medications of the patients with control group. was seen in an analysis of angiostatin and comorbidities in the patient group; however, a significantly higher level of angiostatin was measured in the patients with comorbidities when compared with the control group (Table 2).

\section{Discussion}

To the best of our knowledge, this cross-sectional trial evaluating and demonstrating the importance of serum angiostatin levels in HF patients with CKD is the first. The primary novel findings of this study indicated that serum levels of angiostatin were markedly increased in $\mathrm{HF}$ patients with CKD compared with healthy subjects. Also, significantly higher angiostatin levels were determined in HF patients with CKD patients receiving beta blocker therapy versus those in the patient group who were not using a beta blocker.

Angiostatin has been a focus of study for the treatment of cancer and it has been shown to be an effective antiangiogenic agent. Some data have been reported concerning the involvement of angiostatin in angiogenesis and inhibition of the mesenchymal stem cell $[12,13]$.

There are also studies demonstrating a change in angiostatin level in the presence of kidney disease. Basile et al. [10] demonstrated that local synthesis of angiostatin following acute kidney disease in rat models suggested a possible role for angiostatin in this activity and furthermore, angiostatin expression did not occur in a healthy rat kidney. In addition, Tianfu et al. [14] demonstrated a significant elevation of angiostatin in the urine of patients with lupus nephritis. 
Yamahara et al. [15] reported that the angiostatin level in dilated cardiomyopathy patients was significantly higher than that of the healthy individuals. In a mouse experiment, Srikanth et al. [16] found increased angiostatin in hypertrophic cardiomyopathy. A progression to tubular hypoxia/ischemia has to be considered due to the anti-angiogenic effects of angiostatin.

There is a lack of studies demonstrating changes in systemic concentrations of angiogenic factors in HF patients with CKD. Angiostatin could be an important physiopathological molecule in HF patients with CKD, considering its role in depressing neovascularization in CKD patients and given the results of increased serum angiostatin levels in CKD patients in the present study. Additionally we observed significantly higher levels of angiostatin in HF patients with CKD and comorbidities than in the control group. However, we did not observe a significantly high level of angiostatin in a specific HF patient group. Therefore, we do not think the comorbidities in the patient group affected the angiostatin level in HF patients with CKD.

Another important finding was the medication-angiostatin association observed in our HF patients with CKD. A significantly higher angiostatin level was seen among HF patients using beta blocker therapy than in those who did not. There is some research in the literature about the effect of beta blockers on angiogenesis related to the effects of propranolol in infantile hemangioma and the anti-angiogenic effect of beta blockers in breast cancer patients $[17,18]$. According to our findings, we hypothesize that the use of beta blockers may reduce angiogenesis via increasing angiostatin in HF patients with CKD. This may be one of the antiangiogenic and apoptotic mechanisms of beta blockers in this patient population. There was no significant difference in the patient group when comparing the use of medications other than a beta blocker. We hypothesize that other medications do not affect the angiostatin level in HF patients with CKD.

The current study is an analysis of only 1 anti-angiogenic agent, angiostatin, which makes it hard to reveal the angiogenic/anti-angiogenic factors in HF patients with CKD. In addition, the number of participants in this study is limited, and thus cannot ascertain whether these findings apply to other HF patients with CKD. Nonetheless, we think that the present study is significant in that these findings have not been demonstrated before in the literature. Further clinical trials with a larger number of participants are necessary for confirmation of the current results.

\section{Conclusion}

Circulating angiostatin levels were found to be higher in $\mathrm{HF}$ patients with CKD. Beta blocker use may harm angiogenesis in HF patients with CKD by increasing angiostatin levels through the effect on angiogenesis and apoptosis. Our results suggest that targeting neovascularization might be a novel approach to retard the progression of HF patients with CKD.

\section{Conflict of interest: None declared.}

Ethics Committee Approval: This study was approved by Gulhane Education and Research Hospital local ethics council with protocol number 1491-181-12/1539-491 on February $28^{\text {th }}, 2012$.

Financial Disclosure: None declared.

Peer-review: Externally peer-reviewed.

Authorship contributions: Concept - I.E.; Design - T.O.; Supervision - K.S.; Fundings - R.A.; Materials - R.A.; Data collection \&/or processing - I.E.; Analysis and/or interpretation - F.Y., E.S.; Literature search - B.Y.; Writing - I.E.; Critical review - F.N.A.

\section{References}

1. Denic A, Mathew J, Lerman LO, Lieske JC, Larson JJ, Alexander MP, et al. Single-Nephron Glomerular Filtration Rate in Healthy Adults. N Engl J Med 2017;376:2349-57. [CrossRef]

2. Abboud H, Henrich WL. Clinical practice. Stage IV chronic kidney disease. N Engl J Med 2010;362:56-65. [CrossRef]

3. Levey AS, Eckardt KU, Tsukamoto Y, Levin A, Coresh J, Rossert $J$, et al. Definition and classification of chronic kidney disease: a position statement from KidneyDisease: Improving Global Outcomes (KDIGO). Kidney Int 2005;67:2089-100. [CrossRef]

4. McMurray JJ, Adamopoulos S, Anker SD, Auricchio A, Böhm M, Dickstein K, et al; ESC Committee for Practice Guidelines. ESC Guidelines for the diagnosis and treatment of acute and chronic heart failure 2012: The Task Force for the Diagnosis and Treatment of Acute and Chronic Heart Failure 2012 of the European Society of Cardiology. Developed in collaboration with the Heart Failure Association (HFA) of the ESC. Eur Heart J 2012;33:1787-847.

5. Ponikowski P, Voors AA, Anker SD, Bueno H, Cleland JGF, Coats AJS, et al. 2016 ESC Guidelines for the diagnosis and treatment of acute and chronic heart failure: The Task Force for the diagnosis and treatment of acute and chronic heart failure of the European Society of Cardiology (ESC)Developed with the special contribution of the HeartFailure Association (HFA) of the ESC. Eur Heart J 2016;37:2129-200. [CrossRef]

6. Praidou A, Androudi S, Brazitikos P, Karakiulakis G, Papakonstantinou E, Dimitrakos S. Angiogenic growth factors and their inhibitors in diabetic retinopathy. Curr Diabetes Rev 2010;6:304-12. [CrossRef]

7. Tatar M. Management of diabetes and diabetes policies in Turkey. Tatar Globalization and Health 20139;2-7.

8. Griscelli F, Li H, Bennaceur-Griscelli A, Soria J, Opolon P, Soria $C$, et al. Angiostatin gene transfer: inhibition of tumor growth in vivo by blockage of endothelial cell proliferation associated with a mitosis arrest. Proc Natl Acad Sci U S A 1998;95:636772. [CrossRef]

9. Moser TL, Stack MS, Asplin I, Enghild JJ, Højrup P, Everitt L, et al. Angiostatin binds ATP synthase on the surface of human endothelial cells. Proc Natl Acad Sci U S A 1999;96:2811-6.

10. Basile DP, Fredrich K, Weihrauch D, Hattan N, Chilian WM. Angiostatin and matrix metalloprotease expression follow- 
ing ischemic acute renal failure. Am J Physiol Renal Physiol 2004;286:F893-902. [CrossRef]

11. Levey AS, Stevens LA. Estimating GFR using the CKD Epidemiology Collaboration (CKD-EPI) creatinine equation: more accurate GFR estimates, lower CKD prevalence estimates, and better risk predictions. Am J Kidney Dis 2010;55:622-7. [CrossRef]

12. Cao Y, Xue L. Angiostatin. Semin Thromb Hemost 2004;30:8393. [CrossRef]

13. Cao Y. Antiangiogenic cancer therapy. Semin Cancer Biol 2004;14:139-45. [CrossRef]

14. Wu T, Du Y, Han J, Singh S, Xie C, Guo Y, et al. Urinary angiostatin-a novel putative marker of renal pathology chronicity in lupus nephritis. Mol Cell Proteomics 2013;12:1170-9. [CrossRef]

15. Yamahara K, Min KD, Tomoike H, Kangawa K, Kitamura S, Na- gaya N. Pathological role of angiostatin in heart failure: an endogenous inhibitor of mesenchymal stem-cell activation. Heart 2009;95:283-9. [CrossRef]

16. Givvimani S, Tyagi N, Sen U, Mishra PK, Qipshidze N, Munjal C, et al. MMP-2/TIMP-2/TIMP-4 versus MMP-9/TIMP-3 in transition from compensatory hypertrophy and angiogenesis to decompensatory heart failure. Arch Physiol Biochem 2010;116:63-72.

17. Li D, Li P, Guo Z, Wang H, Pan W. Downregulation of miR-382 by propranolol inhibits the progression of infantile hemangioma via the PTEN-mediated AKT/mTOR pathway. Int J Mol Med 2017;39:757-63. [CrossRef]

18. Childers WK, Hollenbeak CS, Cheriyath P. $\beta$-Blockers Reduce Breast Cancer Recurrence and Breast Cancer Death: A MetaAnalysis. Clin Breast Cancer 2015;15:426-31. [CrossRef] 